(REVIEW ARTICLE)

\title{
Morality and ethics in research
}

\author{
Chima Ichendu * \\ Department of Architectural Technology Captain Elechi Amadi Polytechnic, Rumuola, Port Harcourt.
}

Publication history: Received on 01 December 2020; revised on 09 December 2020; accepted on 11 December 2020

Article DOI: https://doi.org/10.30574/wjarr.2020.8.3.0470

\begin{abstract}
Morality and ethics as a concept suggest the consideration of good versus evil in the light of the principles that govern an institution. However, this notion is not without due argument on what could be read and interpreted as morality and the guiding principles referred to as ethics particularly in research. Furthermore, scholars has it that certain research work in the past infringed on human and animals species. This brought about the quest for a mitigation strategy, one of the strategies includes formation of committee known as ethics committee, who are empowered to formulate framework/codes as acceptable/guiding principles, reference for further research work which aid the reduction in the level of infringement. The essay appraised several literatures geared towards answering the essay questions.
\end{abstract}

Keywords: Ethics; Morality; Theories; Framework and codes

\section{Introduction}

The primary aim of research is the expansion of knowledge through specific processes. This activity of furthering knowledge necessitates the involvement of researchers who are to conduct the activity in a manner that portrays integrity. However, due to cases of infringement and dispute such as the famous syphilis case - a research guiding framework was drafted to ensure that the adoption of this concept of ethics and morality in every research work to foster smooth exercise and elimination of further errors. Regardless of the institution in which they occur, the panel which oversees this observance of ethical standards in research is called the Ethical Committee, whereas the body of rules created to preserve the integrity of the research process is referred to as Ethical and Morality principles.

Despite the above efforts, disputes exist concerning the standards which inform the adopted ethical and morality principle; with opinions varying widely as regards the relativism of morality in the research arena. Hence, what one scholar might consider ethical may not be acceptable by the next scholar. Nevertheless, this great debate has managed to reach a general consensus stating that morality and ethics can be viewed through basic theories known as ethical and morality theories-the virtue, the consequentialist, and the deontological theories.

Presented in this paper is the basic and generic notion on the theories as a guide towards the understanding of what could possibly become an acceptable standard of the notion of morality and ethical values - subject to the perspective of each of the theories mentioned above. These theories in themselves have stirred several debates. Nevertheless, one could possibly point out a common understanding of the terms, showing that they essential share a common goal; either taking cognisance of the consequences of every action, the action itself or the actor as the bases for judgement. These theories form the common understanding of what forms acceptable principles which, in turn, form the framework by which ethics and morality is judged, particularly as regards the area of research. Additionally, since the theories are tied to either the action, the actor or its consequences, the understanding here is that the researcher should be abreast of these notions and apply them accordingly during the research exercise.

\footnotetext{
* Corresponding author: Chima Ichendu

Department of Architectural Technology Captain Elechi Amadi Polytechnic, Rumuola, Port Harcourt.
} 
Appraised in this assignment are literatures on ethics, morality and research in a bid to answer the question from the class work. Hence, this paper presents the basic definition of key themes, the concept of ethics and morality, the importance of ethics and morality in research, codes and policies for research ethics as well as ethical principles and concludes with discussion of the subject, ethics and morality in research.

\section{Definitions of key themes}

Morality is the behavioural belief of wrong and right. It could also be defined as a certain degree that is defined as right or wrong (Hammersley \& Traianou, 2017). Ethics, on the other hand, is a branch of study concerned with what makes up good and bad behaviour; a philosophical range that engages itself with the question of what is morally right and wrong (Kamat, Prashant V, 2006). Furthermore, the term Research refers to a formal, systematic application of scientific approach to study of a problem to discover new information or expand and verify existing knowledge (Hickey, 2018).

Ethics and morality as a concept was borne from the issues encountered in the course of advancing knowledge through research. Hence, they were formed as a precautionary measure against future regarding integrity in research. In essence, the principle of ethics and morality in research was formed to eliminate/reduce ethical lapses and simultaneously solve new ethical challenges and problems such as those recorded by Hickey, (2018) in the cases of the Nazi experiment in WW2 and Tuskegee syphilis study which was documented in the Nuremberg Code, in the declaration of Helsinki and Belmont report.

\section{The concept of ethics and morality}

Essential to the discussion of the concept of ethics and morality are certain theories to which it's definition is subject. According to Hickey, (2018); Gamlund, (2012) and Kaptein \& Wempe, (2002), normative ethics is informed by multiple theories which form the foundation for determining what moral conduct entails. These are the deontological, consequentialist and virtue theories.

Deontological ethics bases its definition of morality on the action for moral evaluation while the consequentialist theory views morality as the real and expected consequence of the action. The virtue theory, however, deals with the intent of the action (Kaptein \& Wempe, 2017).

Consequentialist ethics states that what could be read as a good moral is dependent on the consequence of the action taken. Hence, if the consequence is good, then the deed can be regarded as good as well. On the other hand, if the consequence is bad, then so is the action. Furthermore, the consequentialists believe that actions are taken to ascertain a set goal. These said action(s) are further divided into the categories of instrumental and intrinsic. In instrumental theories, the end/goal is used to attain a distance goal while, in the intrinsic theories, the end is employed for their sake. Kaptein and Wempe (2002) further posit that amongst the two theories, the intrinsic is often used and is divided into monistic and pluralistic- in the monistic theories there is only one of such intrinsic end while the pluralistic, there are more than one of such intrinsic end (Gamlund, 2012).

Deontological believe in the distribution of certain non-negotiable obligations to all, implying that one's obligation cannot be bought or disposed. This entails that different kinds of inalienable rights are the bases of their obligations. Hence, obligation of the action is an important factor to be considered in determining whether the action is morally good or bad. This translates to morality being defined as honouring ones obligation while immorality as dishonouring ones obligation. Nevertheless, deontological ethics believe that behind every obligation are illegalities and unjust actions which are prohibited while legitimate and just actions are acceptable. Furthermore, deontological ethics holds that certain actions and its consequences are spelt and embedded in it and therefore becomes the measurement for such obligations and rights. Thus, the principle to which an action corresponds is the major determinants of what is termed right or wrong morals.

Unlike the above theories, the virtue theory does not base its judgement on either the action or its consequences. Rather it employs the personality of the actor as its analytical tool. Hence, its evaluation is tied to the persons that act and the intentions which guide them. The judgement of virtue ethics regarding what is morally good or bad is associated to the tangible attributes of such individual ability and motives. Ability and motives in this context are the determining factors in the evaluation of moral traits of such a person. Virtue can be defined as the capability of something or someone to achieve a specific target/goal-the expected capacity of an individual to perform a given task. Hence, virtue ethics is the formulated theoretical norms/obligation that align with the moral characteristics or qualities of an individual. 


\section{Ethical principles}

There are guiding rules which conduct every realm of life. In ethics and morality, these basic rules are referred to the principles. This principles are reflected in; Honesty, objectivity, integrity, carefulness, openness, respect for intellectual property, confidentiality, responsible publication, respect for colleagues, social responsibility, non-discrimination, competence legality, animal care, and human subjects protection all jointly make up the universal ethical principles (Resnik, 2015). These principles are elaborated in the next Section of this essay.

\section{Importance of ethics and morality in research}

The significance of ethics and moral norms in research cannot be overemphasised. However, it is only made effectual when it is adhered to. Thus a guiding rule, would aid members to undergo studies within a given set standard, preventing anomalies in the advancement of knowledge such as falsification, fabrication as well as misrepresentation of research data (Paul, Jhangiani, \& Chiang, 2013). These principles promote truth and reduce errors. Furthermore, taking into consideration the fact that research is rarely done in isolation but through coordination and cooperation amongst peers, or class, in many cases with different/same institutions; it is pertinent to note that ethical standards aids the promotion of values which are essential for collaborative works.

Some of these values include, but are not limited to; accountability, fairness, mutual respect and trust. Furthermore, these ethical values and norms in research are likely found in the cases of confidentiality rules enshrined in peer review, data sharing policies, copyright as well as guidelines for authorship which are fashioned as protective measures for the interest of intellectual properties as well as encouragement for collaboration Rezink (2015) emphasised. These codes also serve as tools to prevent idea theft/premature disclosure and awarding credence for contributors in research.

Additionally, morality and ethical values promotes the assurance that scholars can be held accountable by the public. In essence, scholars who receive grants for a research work should be able to account for the grant obtained. To this effect, policies on research misconduct, conflicts of interest, human subjects' protection as well as animal care are necessitated as policing agent against defaulters (Paul, et al., 2013). Finally, values and norms to be observed in the course of research promotes a variety of other significant social values and morals such as human rights, animal right/welfare, social responsibility, public health and safety compliance with the law. This is crucial as a scholar who defaults in any of these principles can cause harm to human, animal subjects, students and the public significantly. While breaking new ground in course of advancing knowledge through research, the adherence to ethical phenomena enables the research to align with moral standard acceptable in line with the standards and ethics governing research (Paul, et al., 2013and Rezink 2015).

\section{Codes and Policies for Research Ethics}

With regard to the peculiarity and significant nature of ethics in carrying out research, each institution, government agencies and parastatals inclusive, have enshrined in their policies what is ethically and morally accepted principles and standard referred to as code of ethics.

It is important that scholars maintain a standard of honest in reporting all found information and data in course of research work; the information should be duly recorded in its original form and referenced. Likewise, the objectivity of the research work should be spelt out and adhered to. Both the researcher and his/her research work should fully display integrity (Paul, et al., 2013 and Rezink 2015). It is no news that research work demands the maximum amount of caution and precision, this virtue should be applied to every area, citation and referencing inclusive. Respect for intellectual properties is revealed in the citing, referencing and acknowledging of all materials obtained from the works of other scholars.

Furthermore, the researcher should maintain confidentiality where it is required. Their research works must also be accountable. In the vein, responsible publication and mentorship cannot be over emphasised. It is also significant that the researcher display social responsibility and portray zero discrimination in his/her work. Responsible research approach must be adhered to by all relevant institutions as to allow for legality. Finally, absolute care should be accorded on all animal and human subjects (Fouka \& Mantzorou, 2011). 


\section{Conclusion}

From a single perspective, the several theories surrounding the concept of ethics and morality can be complex to grasp. From the presented themes above, it is evident that the definition of what is ethical and moral and what is not can be informed by multiple standards. With the multiplicity of theories - from virtue, to deontology and even consequentialism - come these multiple standards and inherent relativism regarding the basic parameter for the evaluation morality.

As a researcher, it is essential that one is informed of all these theories as it aids the subjective understanding of what is morally good and bad from various point of view. Though the difference in these perspectives have caused debates amongst scholars, it is essential to view them from a unifying angle. Hence, one may recognize that they are essential for the understanding of individual roles such as the action, consequence and the actor. Fused together, they produce an acceptable paradigm in research which effectively eliminates infringement and to averts future crisis and as a guide in the course of undertaking research activities; particularly concerning research that pertains to human and other animate organisms.

Nevertheless, it will not be out of place to mention that, despite adhering to the rules governing research, the researcher should ensure that the research methodologies, brief should be sent to the ethics committee and obtain ethics certification, ascertaining that the research methods has in it all ethical guides.

\section{Compliance with ethical standards}

\section{Acknowledgments}

I acknowledge the push and encouragement of my friend and brother Mr. Alexander Budnukaeku Chinago for the completion of this paper and the final Publication. Your really a brother.

\section{Disclosure of conflict of interest}

None

\section{References}

[1] Fouka G, Mantzorou M. What are the Major Ethical Issues in Conducting Research? Is there a Conflict between the Research Ethics and the Nature of Nursing? HEALTH SCIENCE JOURNAL. 2011; 5(1): 3-14.

[2] Gamlund E. ethics. (pp. 1-90). Bergen: University of Bergen. 2012.

[3] Hammersley M, Traianou A. Ethics and educational research, London: TLRP. Retrieved February 17, 2017, from http://www.tlrp.org/capacity/rm/wt/traianou [Google Scholar]

[4] Hickey C. Research Ethics in Social Research. centre for Effective Services (pp. 1-76). Dublin, Ireland: centre for Effective Services. 2018.

[5] Kamat Prashant V. Research Ethics. In I. L. V (Ed.), Committee on Science, Engineering and Public Policy. 2006; 149.

[6] Kaptein M, Wempe J. the general theories of ethics and the integrative role of integrity thoery. SSRN Electronic Journal. 2017; 1-52.

[7] Paul PC, Jhangiani R, Chiang, I.-C.-A. Moral foundation of Ethical Research. Canada: Creative commons attributionnoncomercial-shareAlike 4 (pressbooks open book Publishing). 2013.

[8] Resnik DB. What is ethics in research and why is it important. United State: National Institute of Enviornmental Health Science. 2015. 